\title{
Current and future aspects of the digital transformation in the European Steel Industry
}

\author{
Teresa Annunziata Branca ${ }^{1}$, Barbara Fornai ${ }^{1}$, Valentina Colla ${ }^{1, *}$, Maria Maddalena Murri ${ }^{2}$, Eliana Streppa ${ }^{2}$, \\ and Antonius Johannes Schröder ${ }^{3}$ \\ ${ }^{1}$ Scuola Superiore Sant'Anna, TeCIP Institute, ICT-COISP Center, Pisa, Italy \\ 2 RINA CONSULTING - Centro Sviluppo Materiali S.p.A. (CSM), Castel Romano (Roma), Italy \\ 3 Technische Universität Dortmund, Dortmund, Germany
}

Received: 4 October 2020 / Accepted: 8 March 2021

\begin{abstract}
The technological transformation in the European steel industry is driven by digitalization, which has the potential to strongly contribute to improving production efficiency and sustainability. The present paper describes part of the work developed in the early stage of the project entitled "Blueprint 'New Skills Agenda Steel': Industry-driven sustainable European Steel Skills Agenda and Strategy (ESSA)", which is funded by the Erasmus Plus Programme of the European Union. The project aims at achieving an industry driven, sustainable and coordinated blueprint for addressing the economic, digital and technological developments, as well as increasing energy efficiency and environmental demands through continuously update of qualification, knowledge and skill profiles of the workforce. On the one hand, main aspects of the current state of the technological transformation in the steel sector are described through the analysis of the main recent innovation projects and developments. On the other hand, survey results from a dedicated questionnaire addressed to the European steel companies are analyzed, providing an overview on the (planned) technological transformation affecting the steel sector. The existing levels of plant automation and the possible adoption of the new paradigm of Industry 4.0 are discussed, by also considering the possible impact on the workforce. Main results are that the steel industry foresees an implementation of almost all Industry 4.0 technologies not only for competitive but also environmental improvement. Because this is foreseen in an incremental way upskilling of the existing workforce is a precondition, not only because of recruitment difficulties on the employment market but also because the existing qualification and experience of the workplace is necessary to unfold the full potential of digital and green transformation.
\end{abstract}

\section{Introduction}

The current industrial transformation results from several industrial revolutions over the last two hundred years. From the late 1800s and early 1900s Industry 1.0, based on the mechanization of work, led to the electrification of work of Industry 2.0. After this period, in the early 1960s, the automation of work characterized Industry 3.0. More recently, in the first decades of the new millennium the digitalization of information, supporting the intelligent automation and the ever-increasing computational resources, characterized Industry 4.0. The term Industry 4.0, originated in Germany [1,2], indicates the fourth technological revolution and refers to the implementation of advanced automation solutions in production technologies, supported by a variety of digital technologies. Such concept

\footnotetext{
* e-mail: colla@sssup.it
}

includes machine-to-machine communication, Artificial Intelligence (AI) [3] and Industrial Internet of Things (IIoT) [4] for improving self-monitoring, diagnostic, forecasting and self-optimization [5] capabilities of automation systems [6]. Industry 4.0 was considered a new industrial stage, where different emerging technologies are converging to provide digital solutions, leading to the smart factory concept [7]. Concerning the steel sector, the 1st industrial revolution was characterized by the introduction of coal-powered steel engines. It represents the first fundamental shift in the optimisation of industrial processes, leading to productivity increase and to first interactions between workers and machine tools. The 2nd Industrial Revolution was characterized by the invention of the production area, the improvement of transportation technologies and the electrification of industrial processes. These aspects led to produce cheaper steel through the Bessemer process and to introduce the open-hearth furnace. The 3rd Industrial Revolution was based on the 
introduction of a progressive automation of manufacturing, reducing manual work and increasing the industrial production. In addition, the development of work in assembly lines, focusing on optimisation and removal of inefficiencies, and based on the integration of computers to control the whole production process, represented a key aspect [8]. Finally, in Industry 4.0 breakthrough innovations have been integrated in process automation, including Cyber Physical Systems (CPS), Big Data analytics and Decentralised Control Systems. In particular, CPS are composed of physical subsystems equipped with computing and networking resources/facilities to monitor and control physical processes, where physical processes affect computations and vice-versa [9]. In addition, big data analytics refer to processing of large, heterogeneous and unstructured process and product data for identifying quality problems and reducing the product failures [10,11]. Finally, self-organizing production is related to the decentral solutions based on a new combination of resources, equipment, and personnel, with a close mutual interaction and supported by distributed computational resources, leading to the real-time control of production networks [12].

However, it has to be stated, the industrial development phases from Industry 1.0 to 3.0 could not be seen as a linear and positive development process. According to Schumpeter's Creative Destruction [13] the industrial revolutions are compared by societal injuries (job losses, emissions, deaths of workers, etc.). If this will be the same for the 4th industrial is not quite consensual: While some scholars expect disruptive changes [14], others foresee mainly incremental impact via innovative technologies updating and supporting of existing procedures (esp. because of the already existing high automation of production processes) and new jobs appearing [13,15]. Concerning the workforce implications, equivalent scenarios are under discussion: from substitution of work via robots and related massive job losses over the polarization, to higher and lower qualifications and tasks (by decreasing the middle operative level), as well as new cooperation between different levels and working areas, and crowd working on virtual or digital connected platforms [16,17]. In the transformation of manufacturing industry digitalization is considered as a core technology. It is expected to impact and transform industry, mainly through a substantial improvement of the entire value chain. Nevertheless, its effective implementation in the business activities continues to be slow [18]. In the incoming years, the most important drivers that professionals and decision makers need to take into account are sustainability, digital transformation, innovation and entrepreneurship [19].

In order to measure the achieved level of digitalization in a country, the European Commission developed a composite measure (the Digital Economy and Society Index (DESI), ) summarizing indicators related to the digital performance and digital competitiveness of the European Union (EU) member states [20]. According to [21], the way to implement the Industry 4.0 paradigms consists in integrating technologies, enabling ecosystems of intelligent, autonomous and decentralised industries and integrated product-services. The expected results concern the reduction of the complexity of industry operations, as well as the increase of their efficiency and the reduction of costs. In this scenario, for instance, a new cross-functional business unit (DIGI\&MET) was developed in order to implement new plant design concepts, based on digital innovation, and also new business models [22].

In the incoming years, the adoption of the new digital technologies, particularly based on advanced automation and AI, is expected to produce significant transformation in industrial activities, although this transformation is already underway. Promotion of economic growth and industrial competitiveness is expected. In addition, the increase of digitalization in the industrial environment will lead to recruitment of younger workforce, which is generally more familiar with digital tools. However, some negative aspects for economy and labor market can affect companies, such as skill shortages and mismatches, increased labor costs, production losses due to unfilled vacancies, and higher social costs due to higher unemployment rates [23]. In this context, the European steel industry is driving innovation in digital and green technologies, and plays a key role in progress, economic growth, and job opportunities [24]. This sector is highly specialised in production and implementation of cutting-edge technologies and high value added products and solutions [25] through the investments in Research \& Development \& Innovation (R\&D\&I) [26]. In addition, sustainability and $\mathrm{CO}_{2}$ emissions reduction represent innovative challenges and opportunities for companies to maintain their competitiveness. On this subject, the EU should support the steel sector in the elaboration of an industrial strategy based on innovation, trade, sustainability and skills [27,28].

The concepts of digitization and sustainability are becoming increasingly important and, therefore, they may represent drivers for the evolution of the EU steel industry. In spite of the large research activity on individual concepts like digitalization, digital transformation, Industry 4.0 applications, etc., the interdependency between Industry 4.0 and sustainability was shown. In particular, sustainability is one of the main benefits of Industry 4.0, together with productivity optimization or automated knowledge. In addition, in manufacturing processes, the concepts of Industry 4.0 can enhance operations to improve the environmental sustainability of the production processes $[29,30]$. The aspects related to Circular Economy have a key position in EU policy, as the use of resources and products in a more efficient way can contribute to reduce industrial emissions and to improve EU industrial growth. A recent report [31], including different sectors, such as plastic, cement, aluminum and steel, showed an ambitious circulareconomy scenario by 2050. In addition, digitalization can help to derive, handle, analyse and understand data and complex information flows [32]. Furthermore, it can both catalyse sustainable societies and circular economies, resulting in new industries, new jobs, innovations and opportunities. The circular transformation can provide also innovation and prosperity to labour market and foster economic growth, resulting in more affordable transition costs. 
Concerning future perspectives, research programs and activities play a crucial role for implementing Industry 4.0 concepts in steel industry. For instance, 156 projects, funded by the Research Fund for Coal and Steel (RFCS), involving digitalization and Industry 4.0-related technologies, were recently identified [33]. An investigation about the current research initiatives implementing Industry 4.0 principles and technologies in the EU steel sector was based on an approach including systematic review of funded projects, patents analysis, expert interviews and a qualitative survey of academics and practitioners working in the steel sector [34]. Results showed that Industry 4.0 is perceived as important for the steel sector, and the expected results mainly concern process efficiency and possibility to develop new business models. It is also seen as an opportunity to develop intelligent support systems for the workforce. In addition, the lack of qualified personnel is perceived as one of the main issues. On the other hand, short payback requirements can represent an issue for implementing Industry 4.0. In addition, internal management is considered a driving force for implementing Industry 4.0 projects, due to its cross-cutting nature. Steel manufacturers tend to rely on external expertise and to cooperate with external partners to implement Industry 4.0 concepts and related tools and technologies.

Although some first attempts to apply AI to process modelling and optimization were carried out in the 90-ies, over the last decade the significant evolution and increased availability of computational resources opened far greater opportunities for AI in steelworks. Therefore, nowadays in the steel sector significant technological applications are ongoing. For instance, applications of Big Data and Integrated Intelligent Manufacturing (I2M), as well as applications of AI to process modelling and optimisation are currently being explored to increase energy efficiency $[35,36]$ and reduce $\mathrm{CO}_{2}$ emissions [37,38]. In addition, to reduce energy consumption and environmental impact, new methodological approaches can lead to better management of resources, such as waste materials reduction, recycling improvement, and reduced natural resources exploitation [39-41]. Furthermore, Digital Twins can be used for planning and control plant activities. If products and plants are digitally connected, intelligent automation of processing steps can be achieved, including real-time traceability of objects and their states [42-44].

In a recent review paper, current technological transformations and main developments funded by EU Research Programs were described and analyzed along with impact of digitalization on workforce and economic developments in the steel sector [45]. As highlighted in this work, the future of digitalization in the steel sector will be based on integration, for instance, of Information Technology (IT), automation, optimization technologies, adaptive online control, throughprocess optimization, through-process synchronization of data, zero-defect manufacturing, traceability and intelligent and integrated manufacturing. In addition, the challenge of digitalization is based on vertical, horizontal and transversal integration of systems and production units as well as along the whole lifecycle of the plant production. However, automation of processes already involved the steel production chain, leading to reduction of manual labour.
The recruitment shortage in the steel sector is mainly due to different factors (e.g. lack of adequate profiles, difficult integration of new technologies, in particular among older workers and employees, age gap between current and potential workforce, low investments in training and education, lack of strategies on long-term competences). Even in the transition from Industry 3.0 to Industry 4.0, the main fear was represented by workers' replacement by machinery. In particular, automation and robotic generate new job profiles, but can also produce job losses. For this reason, creation of new jobs and workers' retraining represent significant future challenges [46]. On this subject, potentials and opportunities of human-robot interaction [47] were implemented in a steelmaking process, by also considering a social innovation paradigm [48]. In particular, robot can contribute to improve workers' health and safety conditions by carrying out the most cumbersome activities, while workers supervise the operations [49]. For all these reasons, and due also to skills gaps, mismatches and shortages, the steel industry is committed to face these issues through new strategies and initiatives. They are based on up-skilling and re-skilling programmes to improve interdisciplinary skills and preserve competitiveness. In the context of Industry 4.0, the workforce will be required to interact with digital devices and trust in new technologies, moving away from monotonous and repetitive works. This will lead to improve skills, such as teamwork, problem-solving and decision-making, as well as to a continuous learning process. The implementation of smart and digital components in the steel sector could attract more highly educated candidates. Furthermore, the process to low-carbon competitive steel industry will produce an increasing demand for research engineers and technicians holding competences on material recycling and resource optimization. Strategies for attracting and retaining qualified people, such as educational programs implemented in collaboration with universities and Vocational Education and Training (VET) institutions, can help to enroll more qualified workforce. A recent study was focused on gathering perceptions on current and future steelmaking workforce in the European steel sector from key stakeholders, students, graduates and jobseekers with a STEM (Science, Technology, Engineering, and Mathematics) background [50]. In addition, the main drivers and barriers affecting steelmaking as a possible career choice were identified, with a specific focus on skills supply and demand, aiming at providing a clear understanding of the mismatch between demand and supply to a long-term skill strategy. The work presented in this paper is part of the Erasmus + Blueprint project entitled "New Skills Agenda Steel: Industry-driven sustainable European Steel Skills Agenda and Strategy" (ESSA), started in January 2019. The ESSA project focuses on the development of a Blueprint to achieve sustainability in the steel industry, according to the fast increase of influence and requirements of Industry 4.0. The project aims at improving the competitiveness of the European steel sector via proactive skills adjustment, also including energy efficiency and environmental aspects. Based on continuous training activities, workforce's skill improvements can be achieved, according to the sector demands. In particular, some 


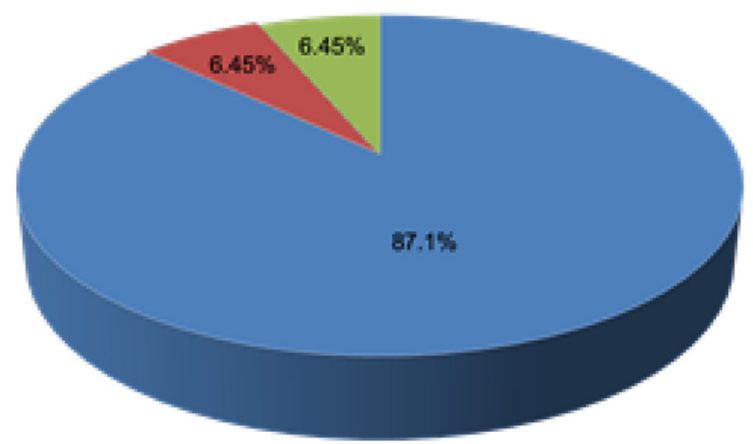

\section{- Large Enterprises =SMEs = Medium Enterprises}

Fig. 1. \% of the enterprises involved in the survey.

significant challenges, crucial for Industry 4.0, can be faced, such as re-skilling of current employees and increased attraction and recruitment of talents. [51,52].

This paper presents a (still limited) first spotlight on the foreseen implementation of Industry 4.0 technologies in the steel sector and its impact on the workforce by the results of a survey carried out to overview the current state of digitalization in European Steel Industry. The existing level of plant automation and the adoption of the new paradigm of Industry 4.0, including the resulting impact on the workforce, were assessed. To this aim, a questionnaire was developed and launched during the early stages of the project, which was addressed to European steel companies.

The paper is organized as follows: Section 2 presents the structure of the questionnaire; then, the survey results are discussed in the Section 3, by considering the planned Strategy, Technical Aspects and Human Resources (HR) impact; finally, in the Section 4 some concluding remarks as well as some notes on the future work are presented.

\section{Structure of the questionnaire}

The survey aimed at collecting information directly from the various company's representatives, concerning the current state of the digitalization in the European Steel Industry. The on-line questionnaire was partly structured and partly unstructured. Structured questions provided a predefined set of responses, while unstructured questions (i.e. questions with open answer) provided deeper information on the respondents' opinion, to explore and collect new ideas. The questionnaire was organized into different sections, as follows: General information, Strategy, Technical Aspects and HR. The first section mainly includes country, company size (e.g. Small and Mediumsized Enterprise-SME, Medium Enterprise, Large Enterprise), type of product, production route and output. The sample considered in the analysis mainly includes large companies (see Fig. 1) located in several European countries, as depicted in Figure 2.

The second section includes questions related to the implemented strategy, such as traditional solutions applied before Industry 4.0, state of digitalization, priorities on digital technologies and which of them will be adopted, how they will affect workforce, company's involvement in research projects on digitalization (past, current and future/planned ones). The third section proposes questions related to technical aspects, such as awareness of opportunities and threats from additive manufacturing, areas of applications of digital technologies, expected benefits and major barriers. The fourth section, concerning HRs, includes questions about gender balance, age profile, percentage of each category of employers with higher education, foreseen evolution of workforce size in the incoming years, awareness of each staff category about digital competences demands, and training programs on Industry 4.0 topics.

The representativeness of the survey results in terms of general information, such as origin country of respondents, company size, production route and product types, was taken into account. In particular, answers primarily involved several professional profiles, e.g. board director, plant managers, Information Communication Technology (ICT) managers, HR managers. In addition, both production routes are represented (i.e. blast furnace route, based on iron ore, and electric route, based on scrap), with a majority of respondents coming from the integrated route. Finally, as far as product types are concerned, they were mainly represented by flat products.

\section{Results and discussion}

\subsection{Strategy}

In the first part of the questionnaire the state of digitalization and plant automation in the steel industry before Industry 4.0 was evaluated. In addition, the level of knowledge and interest on Industry 4.0 enabling technologies were assessed. Results provided significant level $(77,78 \%)$ of automation, while lower levels of Basic Automation (BA) and full Process Integration (PI) were detected. Furthermore, standard solutions, such as Computer Aided Design (CAD), Product Data Management (PDM), production control system, are currently adopted. As shown in Figure 3, results confirm the commitment of European steel companies to technological improvements as a way to increase competitiveness.

The priority and importance for more or less all companies involved in the survey were mainly focused on Internet of Things (IoT), Analytics, Cyber Security and PI, both horizontal and vertical integrations. In particular, PI, mainly based on IoT, allows communication among different units, but also leads to security issues. In particular, IoT concerns a fully connected world, in which various objects networked and connected by collecting and exchanging data and information [53]. An online monitoring system based on IoT architecture is typically composed of four layers: sensing, network, service resource and applications. For instance, a similar system was implemented in a real continuous steel casting production line [54]. Therefore, the listed priorities reflect future trends about interconnectivity and automation.

The survey results showed a general trend about the high awareness of new technologies, although they have not been applied yet. In particular, currently the most investigated and applied technological fields in the steel 


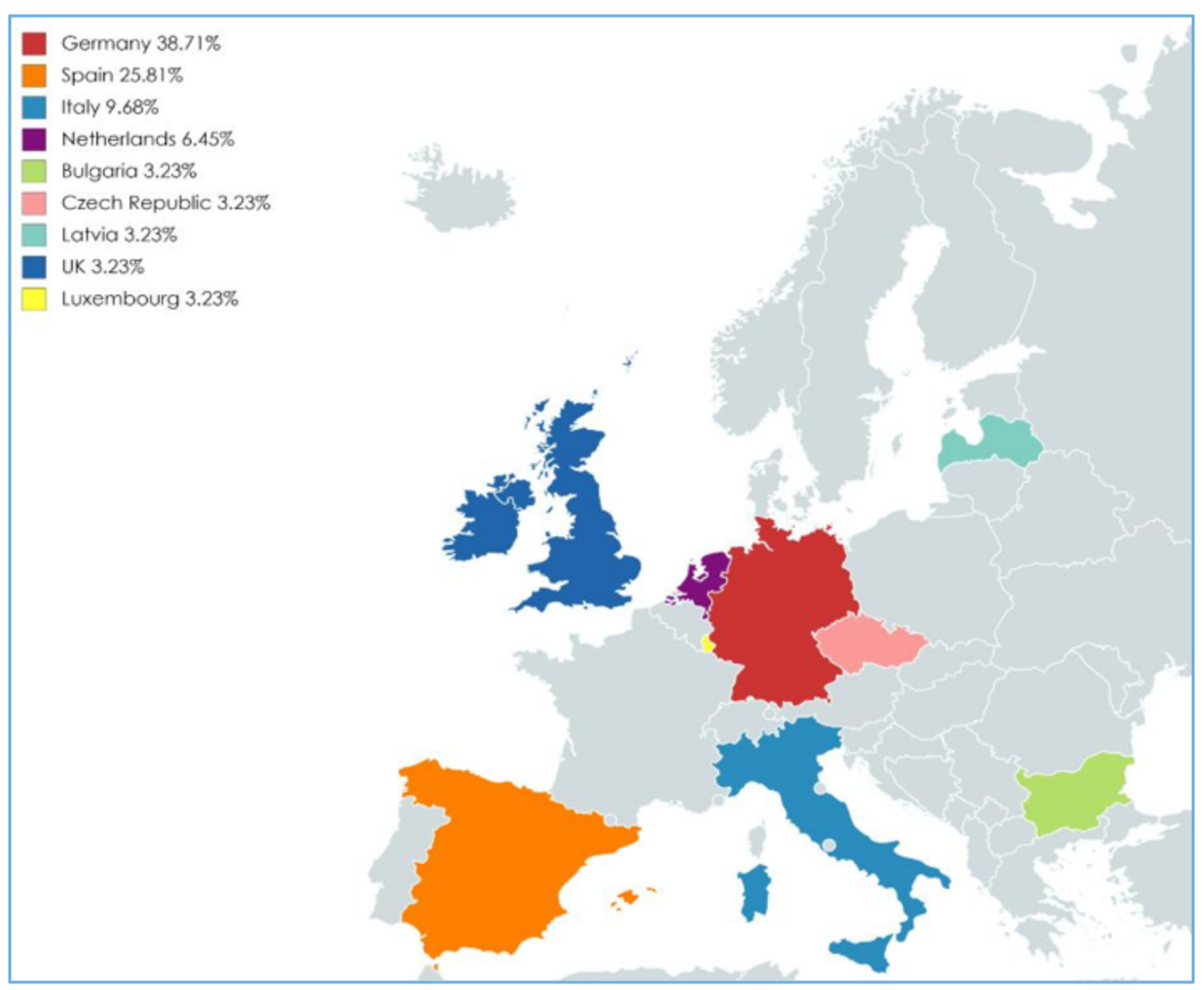

Fig. 2. The European countries involved in the survey.
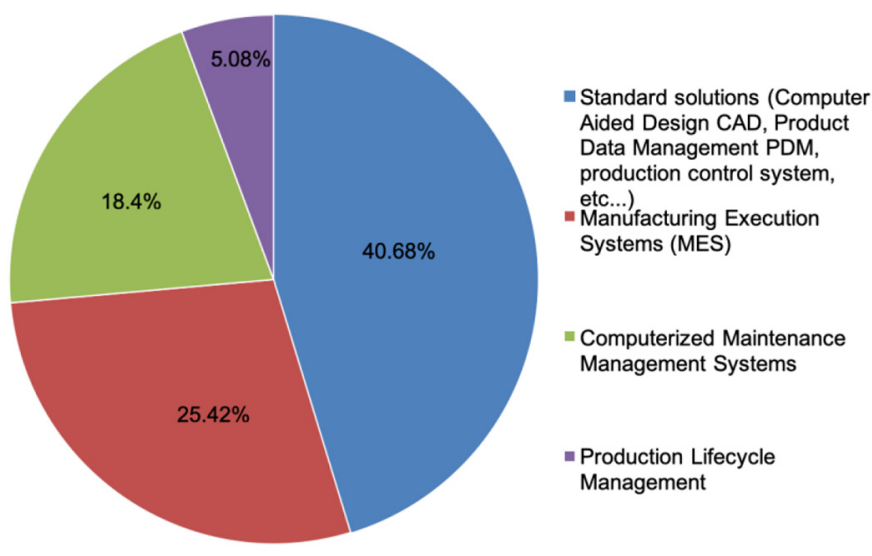

Fig. 3. Traditional solutions currently applied in the European steel companies.

sector are IoT, Cloud Computing, Analytics, Cyber Security and Product/Process Virtual Simulation. Concerning investment plans, results highlighted the strategic relevance of the selected technologies in the short term. In particular, as shown in Figure 4, in the next few years, the investments on Industry 4.0 technologies will be particularly focused on Cyber Security, Analytics and IoT

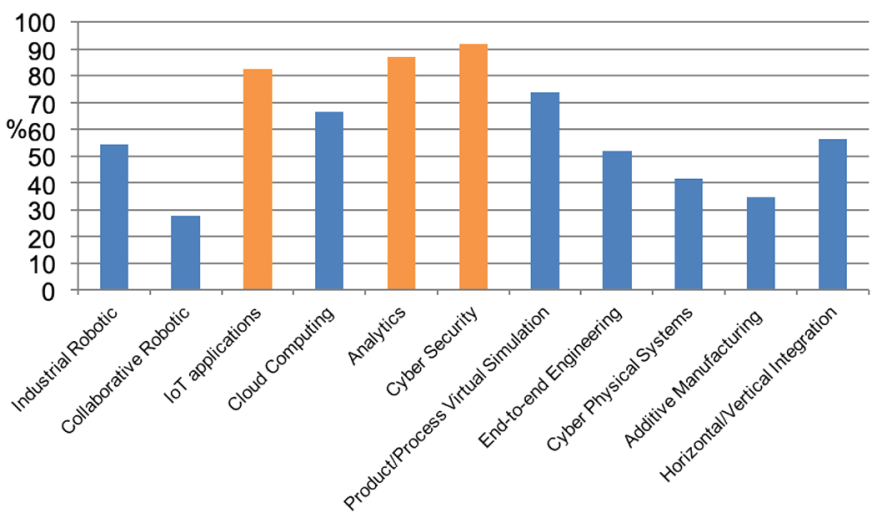

Fig. 4. The planned investments within 3 years.

applications (highlighted in orange in Fig. 4). Additive Manufacturing (AM) is a specific 3D printing process, which in industry makes it possible to build lighter, stronger components and systems, by depositing material according to digital 3D design data. In the steel sector this technology opens up the possibility to develop innovative alloys. The answers of a specific question on AM confirmed some awareness about the opportunities and threats, although AM is not among the main planned investments. 
Management of large amounts of data

Maintenance

Quality control (as decision support)

Administration

HR Management

Customer service

Assistance system

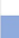

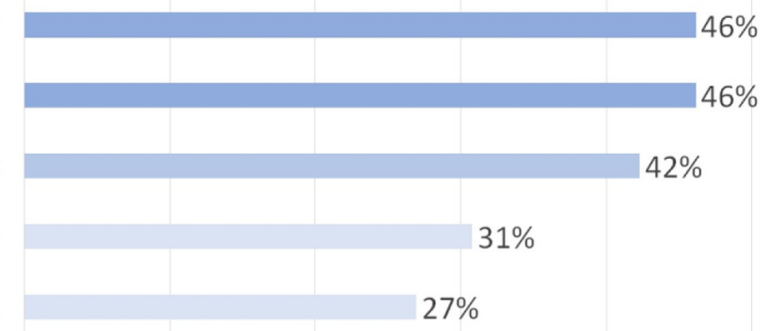

Fig. 5. Digitalization in the areas of companies involved in the survey.

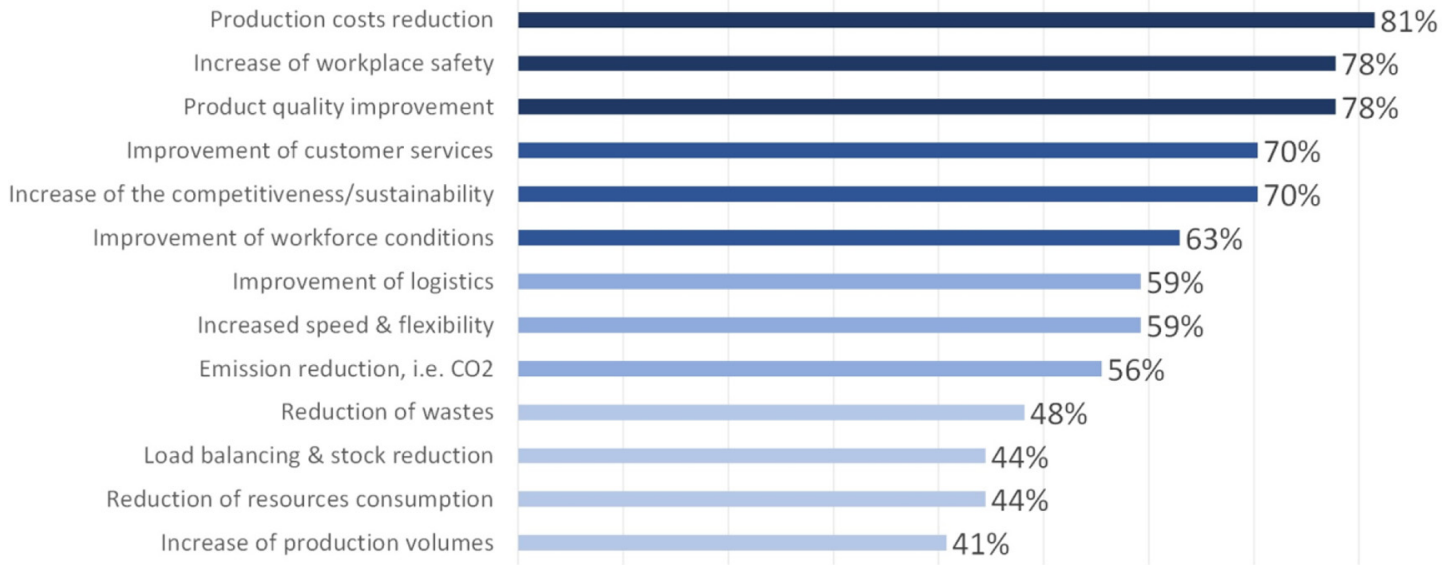

Fig. 6. The expected benefits from adopting enabling technologies.

These results confirm steel industry commitment towards Industry 4.0 through planned investments, to increase its competitiveness.

Concerning the impact of digital technologies on workforce, increasing training, requirement of new skills and upgrading of existing ones were considered as the main impacts, while workforce deskilling was indicated as less affected. On the other hand, impacts on employees were identified, in particular: improvement of work conditions (e.g. workplace), health and safety, increased working time and work-life balance.

Finally, another aspect, which was taken into account in the survey, concerned the participation in the European joint research projects on digitalisation. Results showed the current involvement of some companies, while other ones planned to participate. Nevertheless, significant percentages of the interviewed companies are not involved. In particular, about half is currently involved in few projects $(<5)$ and the remaining is equally divided in up to 10 or more. In addition, increasing interest in joint research projects was detected.

\subsection{Technical aspects}

Concerning the investigated technical aspects, by considering the areas where digital technologies are applied, expected benefits and major barriers to be overcome during their application were considered.

Survey results (see Fig. 5) showed that digital technologies are applied in the process chain control, and where management of large amounts of data is required (i.e. production, business, etc.). In addition, maintenance, administration, quality control and HR management are mainly considered in the application of digitalisation.

Concerning expected benefits from adoption of enabling technologies, results showed a homogeneous distribution of listed benefits (see Fig. 6), with higher results mainly focused on production in terms of cost reduction and quality improvement, as well as on increased workplace safety. In addition, environmental benefits, such as reductions of emissions, wastes and resources consumption, are ranked high in the results. 


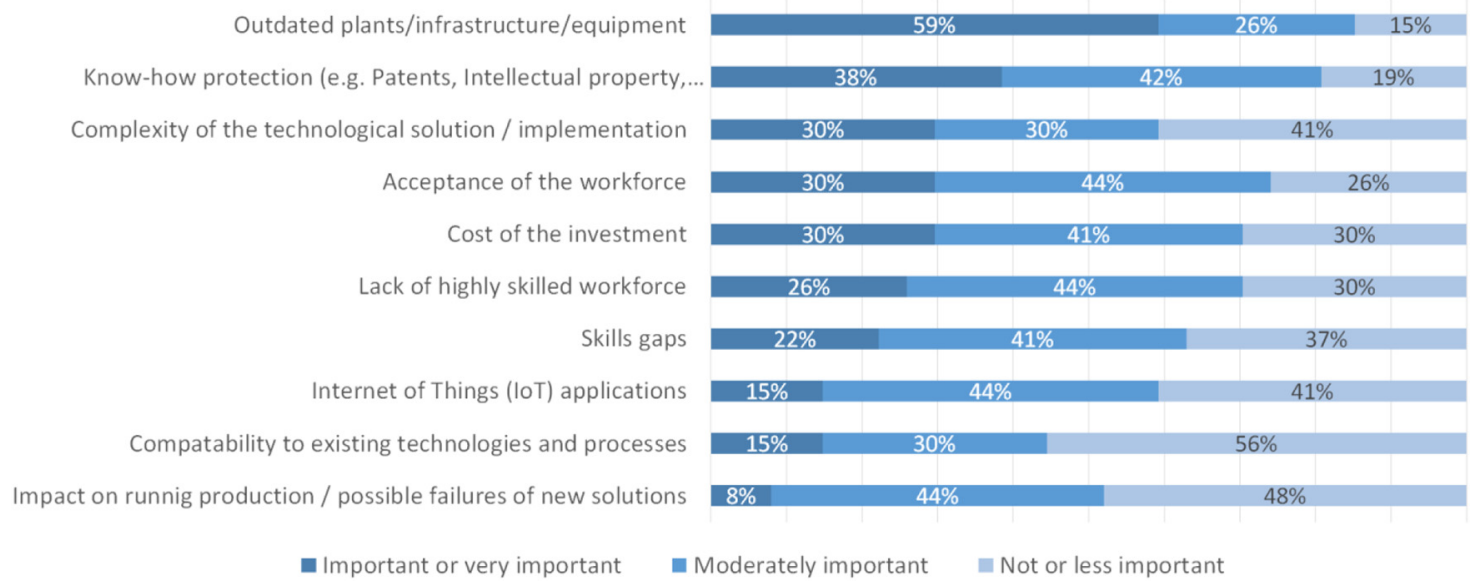

Fig. 7. The distribution of the main digitalization barriers.

Concerning the main barriers affecting adoption and application of new technologies, results were mainly focused on the central categories, based on their importance (Less important, Moderately important, Very important), as shown in Figure 7.

In particular, the proposed barriers were enough uniformly distributed as Moderately important. Furthermore, cost of investment is the most relevant barrier among Important categories. On the other hand, as shown in Figure 7, know-how protection was considered as the least important barrier.

As also shown in Figure 7, the barriers affecting aspects related to workforce, such as lack of highly skilled workforce, skill gap and acceptance of new technologies by the workforce, were highlighted as Moderately important, but they were also pointed out as significant among the important barriers. In addition, obsolescence of plant/ infrastructures and equipment and compatibility with existing technologies and process were highlighted as the most Important barriers.

\subsection{Human resources}

Regarding workforce profiles, focused on HRs and current and future workforce over the last 5 years, age and education were taken into account. Although lack of data and data inhomogeneity were detected, the following aspects were highlighted:

- An imbalance between male and female percentages, with higher percentage of males in all the three considered areas, i.e. operations, administration and services, with the maximum imbalance in the operation area.

- Concerning age profile, the values are reported in absolute value. According to the available valid data, results showed a slight workforce age redistribution during the period from 2015 to 2019. In particular, a certain stability in each presented age class (lower than 25 and between 25 and 34 years old) can be estimated, with a substantial rising in the last two years for personnel from 35-44 years old. On the other hand, the 45-54 age class showed an opposite trend, i.e. a decrease from 2015-2016 to 2019. The last groups (between 55 and
64 years old) showed a stabilization in the overall considered period, while the over 64 age group presented a moderate increase.

- Higher education represents a requisite for most production managers and engineers compared to technicians, operators and apprentices/trainees.

- Concerning workforce development in the next 3-5 years, the sample was subdivided between the increase and the decrease of the trend ( $50 \%$ yes, $50 \%$ no). Nevertheless, the common trend focuses on the increase of women employment, compared to the past, as well as on recruitment of people with higher qualification, to incorporate deeper knowledge and stronger skills for exploiting new technologies.

- A further noticeable aspect is represented by the increased employee awareness related to the need for digital competences. Among the different profiles, production managers and engineers (compared to technicians, operators and apprentices/trainees) were the most aware of the need for digital competences.

Finally, although staff training programs can be crucial to meet Industry 4.0 challenges, results showed that few training programmes are currently scheduled on company's digital products and services, communication, technology and innovation.

\section{Conclusions}

Although this article is a small and initial attempt to analyse the digital and green transition of the steel industry, the results of the conducted survey analysis support a deeper understanding of the companies' trend related to implementation of digital technologies in their production processes and, consequently, about the evolution of workforce skills. In particular, the survey results showed significant levels of automation in the involved steel companies. This represents a starting point for improving technological aspects. Concerning Industry 4.0 technologies, they resulted to be generally widely known. In addition, companies showed interest in IoT, Analytics, Cyber Security and PI (both horizontal and vertical). Some 
of these technologies have already been integrated in the production processes, and are taken into account in planned future investments within short time (i.e. 3 years).

Concerning the impact of the digital technologies on workforce, results highlight the need of improving work conditions, such as workplace environment and health and safety aspects, and increased working time and the worklife balance. In addition, a growing interest in European research projects is highlighted, although no funding programmes are mentioned, and some companies have not been involved in such projects yet.

Currently, digital technologies are applied in all areas of the companies, in particular in process chain control, and in areas requiring management of large volumes of data, e.g. production and business. The expected benefits are mainly dealing with production, such as cost reduction and quality improvement, working conditions in terms of safer and healthier workplaces, and improvement of environmental impacts, such as reduction of wastes, emissions and resources consumptions. On the other hand, the highlighted barriers for adoption and application of enabling technologies concern investment costs. These costs should be assessed by taking into account obsolescence of plant/ infrastructures and equipment. In addition, the compatibility with existing technologies should be considered. Furthermore, the barriers affecting the workforce aspects consist in lack of highly skilled workforce, skills gap and lack of confidence of some workers (especially older ones) in new technologies.

Further discussions in the ESSA project underlines that the impact on the workforce mainly concerns the requirement of T-shaped skills with a focus on horizontal, transversal soft-skills (digital, green, social, methodological, individual and personal skills) as well as the need of continuous learning in an interdisciplinary perspective (and environment). However, the concrete impact of digitalization on the low skilled workers and the effect on employment as well as recruitment difficulties for highskilled workers remain open to further discussion.

As the steel industry is evolving towards industry 4.0 starting mainly from a high level of automation it is more an evolution or incremental adjustment instead of an industrial revolution. The survey and discussions in ESSA stress that the challenge of digitalization concerns the integration of all systems (sensors, automation, and IT systems) and all production units in different dimensions (horizontal, vertical and transversal). In this context, the steel industry's expectations from digital and green transformation concentrate on quality, flexibility and productivity through the optimization and new interactions of the individual production units. Economic aspects include not only the reduction operational costs (i.e. energy/row materials consumption reduction), but also the introduction of new business models and organizational structures.

However, it can already be emphasised that people (or the human factor) are still needed with their experience and skills to implement and run the new systems. Therefore, an integration of technological innovation development within a social innovation process (with co-creation and teamwork) is supporting an effective technological innovation as well as an upskilling of the workforce is needed to unfold the potential of these innovations at the workplace.

As discussed with the stakeholders and companies of the steel industry, even in Industry 4.0 social and organisational factors are still the driver of productivity and innovation. To say it with Klaus Schwab [55], Founder and Executive Chairman of the World Economic Forum: Leaders and citizens "together shape a future that works for all by putting people first, empowering them and constantly reminding ourselves that all of these new technologies are first and foremost tools made by people for people" [48].

The ESSA project, which delivered the described results, is still in ongoing. The questionnaire will remain online to involve additional companies and, consequently, to enlarge the analyzed sample. This will provide increasingly representative data on the situation of the European steel sector about the implementation of the new concepts of industry 4.0 .

Acknowledgments. The research described in the present paper was developed within the project entitled "Blueprint 'New Skills Agenda Steel': Industry-driven sustainable European Steel Skills Agenda and Strategy (ESSA)" and is based on a preliminary deliverable of this project. The ESSA project is funded by Erasmus Plus Programme of the European Union, Grant Agreement No 2018-3019/001-001, Project No. 600886-1-20181-DE-EPPKA2-SSA-B. The sole responsibility of the issues treated in the present paper lies with the authors; the Commission is not responsible for any use that may be made of the information contained therein. The authors wish to acknowledge with thanks the European Union for the opportunity granted that has made possible the development of the present work. The authors also wish to thank all partners of the project for their support and the fruitful discussion that led to successful completion of the present work.

\section{References}

1. H. Kagermann, W. Wahlster, J. Held, Bericht der promotorengruppe kommunikation. Im fokus: Das zukunftsprojekt industrie 4.0, Handlungsempfehlungen zur umsetzung, Forschungsunion, 2012

2. R. Anderl, Industrie 4.0-Technological approaches, use cases, and implementation, At-Automatisierungstechnik 63(10) 753-765 (2015)

3. G. Duft, P. Durana, Artificial intelligence-based decisionmaking algorithms, automated production systems, and big data-driven innovation in sustainable industry 4.0, Econ. Manag. Finan. Mark. 15(4), 9-18 (2020)

4. I. Bisio, C. Garibotto, A. Grattarola, F. Lavagetto, A. Sciarrone, Exploiting context-aware capabilities over the internet of things for industry 4.0 applications, IEEE Netw. 32(3), 108-114 (2018)

5. H.-C. Möhring, P. Wiederkehr, K. Erkorkmaz, Y. Kakinuma, Self-optimizing machining systems, CIRP Ann. 69(2), 740 $763(2020)$ 
6. S.I. Tay, T.C. Lee, N.Z.A. Hamid, A.N.A. Ahmad, An overview of industry 4.0: Definition, components, and government initiatives, J. Adv. Res. Dynam. Control Syst. 10(14), 1379-1387 (2018)

7. P. Osterrieder, L. Budde, T. Friedli, The smart factory as a key construct of industry 4.0: A systematic literature review, Int. J. Prod. Econ. 221, 107476 (2020)

8. L. Gehrke, A.T. Kühn, D. Rule, et al., A Discussion of Qualifications and Skills in the Factory of the Future: A German and American Perspective, VDI The Association of German Engineers, Düsseldorf, Germany, 2015

9. V. Iannino, V. Colla, J. Denker, M. Göttsche, A CPS-based simulation platform for long production factories, Metals 9(10), 1025 (2019)

10. J. Brandenburger, V. Colla, G. Nastasi, F. Ferro, C. Schirm, J. Melcher, Big Data Solution for Quality Monitoring and Improvement on Flat Steel Production, IF AC-PapersOnLine 49(20), 55-60 (2016)

11. M. Vannocci, A. Ritacco, A. Castellano, et al., Flatness Defect Detection and Classification in Hot Rolled Steel Strips Using Convolutional NeuralNetworks, in: Rojas I, Joya G, Catala A, eds., Advances in Computational Intelligence, IWANN 2019, Lecture Notes in Computer Science, Springer, Cham, 2019, 11507 p.

12. V. Iannino, M. Vannocci, M. Vannucci, V. Colla, M. Neuer, A multi-agent approach for the self-optimization of steel production, Int. J. Simul.: Syst. Sci. Technol. 19(5), 20.120.7 (2018)

13. J.A. Schumpeter, Kapitalismus, Sozialismus und Demokratie. 7, Auflage. Tübingen., 1993

14. C.B. Frey, M.A. Osborne, The future of employment: How susceptible are jobs to computerisation?, Technol. Forecast. Soc. Change 114, 254-280 (2017)

15. R.D. Atkinson, J.J. Wu, False alarmism: Technological disruption and the US labor market, Inform. Technol. Innov. Found. ITIF, 1850-2015 (2017)

16. J. Abel, H. Hirsch-Kreinsen, T. Wienzek, Akzeptanz von Industrie 4.0, Abschlussbericht zu einer explorativen empirischen Studie über die deutsche Industrie. München: acatech, 2019

17. Acatech-Deutsche Akademie der Technikwissenschaften, "Kompetenzentwicklungsstudie Industrie 4.0 - Erste Ergebnisse und Schlussfolgerungen", 2016

18. P. Kilimis, W. Zou, M. Lehmann, U. Berger, A Survey on Digitalization for SMEs in Brandenburg, Germany, IFACPapersOnLine 52(13), 2140-2145 (2019)

19. J. Ordieres-Meré, T. Prieto Remón, J. Rubio, Digitalization: An Opportunity for Contributing to Sustainability From Knowledge Creation, Sustainability 12, 1460 (2020)

20. DESI 2018, Digital Economy and Society Index Methodological Note, EU Comm., Bruxelles, 2018

21. C. Santos, A. Mehrsai, A.C. Barros, M. Araújo, E. Ares, Towards Industry 4.0: an overview of European strategic roadmaps, Proc. Manuf. 13, 972-979 (2017)

22. A. Merluzzi, G. Brunetti, Metals industry: Road to digitalization, in: Proc. of 40th International Con-vention on Information and Communication Technology, Electron. Microelectron. (MI-PRO) 2017, 2017, pp. 967-973

23. J. Bughin, E. Hazan, S. Lund, P. Dahlström, A. Wiesinger, A. Subramaniam, Skill Shift: Auto-mation and the Future of Workforce, McKinsey Global Institute, 2018
24. European Commission, The future of European steel. Innovation and sustainability in a competitive world and EU circular economy, Publications Office of the European Union, Luxembourg, 2017

25. European Commission, Steel: Preserving sustainable jobs and growth in Europe, COM (2016) 155 final, European Commission, Brussels, 2016

26. European Commission - Directorate-General for Enterprises and Industry, Study on the Competitiveness of the European Steel Sector - Final report, Ecorys SCS Group, Rotterdam, 2008

27. EUROFER, European steel - A manifesto: 2019-2024, 2019, Available from http://www.eurofer.org/News\%26Events/ News/MANIFESTO\%20European\%20Steel\%202019.fhtml

28. K. Peters, E. Malfa, V. Colla, The European steel technology platform's strategic research agenda: A further step for the steel as backbone of EU resource and energy intense industry sustainability, Metall. Ital. 111(5), 5-17 (2019)

29. A.B.L. De Sousa Jabbour, C.J.C. Jabbour, C. Foropon, M.G. Filho, When titans meet: Can in-dustry 4.0 revolutionise the environmentally-sustainable manufacturing wave? The role of critical success factors, Technol. Forecast. Soc. Chang. 132, 18-25 (2018)

30. V. Colla, I. Matino, F. Cirilli, et al., Improving ener-gy and resource efficiency of electric steelmaking through simulation tools and process data analyses, Matériaux \& Techniques 104(6-7), 602 (2016)

31. Material Economics, The Circular Economy A Powerful Force For Climate Mitigation, 2018, Available from https:// materialeconomics.com/publications/the-circulareconomy

32. A. Larsson, L. Lindfred, Digitalization, circular economy and the future of labor: How circular economy and digital transformation can affect labor, in: The Digital Transformation of Labor: Automation, The Gig Economy and Welfare, 1 st ed., Routledge, 2020, 16 p., DOI: 10.4324/ 9780429317866-16

33. M. Arens, Policy support for and R\&D activities on digitising the European steel industry, Resour. Conserv. Recycl. 143, 244-250 (2019)

34. C. Neef, S. Hirzel, M. Arens, Industry 4.0 in the European Iron and Steel Industry: Towards an Overview of Implementations and Perspectives, Fraunhofer Institute for Systems and Innovation Research ISI, Karlsruhe, Germany, 2018

35. F. Marchiori, M. Benini, S. Cateni, et al., Agent-based approach for energy demand-side management, Stahl und Eisen 138, 25-29 (2018)

36. S. Dettori, I. Matino, V. Colla, V. Weber, S. Salame, Neural Network-based modeling methodol-ogies for energy transformation equipment in integrated steelworks processes, Energy Proc. 158, 4061-4066 (2019)

37. G.F. Porzio, B. Fornai, A. Amato, et al., Reducing the energy consumption and $\mathrm{CO}_{2}$ emissions of energy intensive industries through decision support systems - An example of application to the steel industry, Appl. Energy 112, 818-833 (2013)

38. A. Maddaloni, G.F. Porzio, G. Nastasi, V. Colla, T.A. Branca, Multi-objective optimization ap-plied to retrofit analysis: A case study for the iron and steel industry, Appl. Therm. Eng. 91, 638-646 (2015) 
39. I. Matino, E. Alcamisi, V. Colla, S. Baragiola, P. Moni, Process modelling and simulation of electric arc furnace steelmaking to allow prognostic evaluations of process environmental and energy impacts, Matériaux \& Techniques 104, (2016)

40. I. Matino, V. Colla, F. Cirilli, et al., Environmental impact evaluation for effective resource manage-ment in EAF steelmaking, La Metallurgia Italiana 109, 48-58 (2017)

41. I. Matino, T.A. Branca, B. Fornai, V. Colla, L. Romaniello, Scenario analyses for by-products reuse in integrated steelmaking plants by combining process modeling, simulation, and optimi-zation techniques, Steel Res. Int. 90, (2019)

42. H. Zsifkovits, J. Kapeller, H. Reiter, C. Weichbold, M. Woschank, Consistent Identification and Traceability of Objects as an Enabler for Automation in the Steel Processing Industry, in: Matt D, Modrák V, Zsifkovits H, eds., Industry 4.0 for SMEs, Palgrave Macmillan, Cham, 2020

43. L.-W. Kang, Y.-T. Chen, W.-C. Jhong, C.-Y. Hsu, Deep learning-based identification of steel products, Smart Innovation, Syst. Technol. 110, 315-323 (2019)

44. C.-Y. Hsu, L.-W. Kang, H.-Y. Lin, R.-H. Fu, C.-Y. Lin, M.-F. Weng, D.-Y. Chen, Depth-based feature extraction-guided automatic identification tracking of steel products for smart manufacturing in steel 4.0, in: Proceedings of 4th IEEE International Conference on Applied System Innovation 2018, ICASI 2018, 2018, pp. 145-146

45. T.A. Branca, B. Fornai, V. Colla, M.M. Murri, E. Streppa, A. J. Schröder, The Challenge of Digitalization in the Steel Sector, Metals 10, 288 (2020)

46. D. Autor, A. Salomons, Is automation labor-displacing? Productivity growth, employment, and the labor share, National Bureau of Economic Research, 2018

47. W. Bauer, C. Vocke, Work in the Age of Artificial Intelligence - Challenges and Potentials for the Design of New Forms of Human-Machine Interaction, in: Kantola J,
Nazir S, eds., Advances in Human Factors, Business Management and Leadership, AHFE 2019, Adv. Intell. Syst. Comput., Vol. 961, Springer, Cham, 2020, DOI: 10.1007/ 978-3-030-20154-8_45

48. V. Colla, A.J. Schroeder, A. Buzzelli, D. Abbà, A. Faes, L. Romaniello, Introduction of symbiotic human-robot-cooperation in the steel sector: an example of social innovation, Matériaux \& Techniques 105, 505 (2017)

49. V. Colla, R. Matino, A. Faes, L. Romaniello, A.J. Schröder, Robot-assisted replacement of the refractory components of the ladle sliding gate in a steel shop, in: Proceedings of the 10th European Metallurgical Conference, EMC 2019, Vol. 4, 2019, pp. 1441-1454

50. European Commission, Blueprint for Sectoral Cooperation on Skills: Towards an EU Strategy Addressing the Skills Needs of the Steel Sector: European Vision on Steel-Related Skills of Today and Tomorrow Study, European Commission, Bruxelles, Belgium, 2019, Available from <https://op. europa.eu/en/publication-detail/-/publication/ff0f8660ca07-11e9-992f-01aa75ed71a1>

51. T.W. Malone, The Future of Work. How the New Order of Business Will Shape Your Organization, Your Management Styles, and Your Life, Harvard Business School Press, Cambridge, MA, 2004

52. L.A. Berger, D.R. Berger, The Talent Management Handbook: Creating Organisational Excellence By Identifying, Developing \& Promoting Your Best People, McGraw-Hill, New York, 2004

53. F. Xia, L.T. Yang, L. Wang, A. Vinel, Internet of things, Int. J. Commun. Syst. 25(9), 1101-1102 (2012)

54. F. Zhang, M. Liu, Z. Zhou, W. Shen, An IoT-based online monitoring system for continuous steel casting, IEEE Intern. Things J. 3(6), 1355-1363 (2016)

55. K. Schwab, The Fourth Industrial Revolution, Currency, 2017

Cite this article as: Teresa Annunziata Branca, Barbara Fornai, Valentina Colla, Maria Maddalena Murri, Eliana Streppa, Antonius Johannes Schröder, Current and future aspects of the digital transformation in the European Steel Industry, Matériaux \& Techniques 108, 508 (2020) 